\title{
Aluminum Can to WiFi Trading System with Metal Can and Plastic Bottle Collector and Monitoring System
}

\author{
Edward Panganiban ${ }^{1}$, Bienvenido B. Abad Jr. ${ }^{2}$, Michelle Caranguian ${ }^{3}$ \\ ${ }^{1}$ Isabela State University, Echague, Isabela, Philippines, ebpanganiban @isu.edu.ph \\ ${ }^{2}$ IBSUniversity, Port Moresby Papua New Guinea, bbajr1981@ gmail.com \\ ${ }^{3}$ AMA Computer College, Santiago City, Isabela, Philippines, esonmichiemar@gmail.com
}

\begin{abstract}
Through the decades, the price of aluminum has been accumulative due to economic influences globally. Despite it, people still inclined to overlook the fact that the aluminum scrap thrown away is recyclable and beneficial. The authors have therefore set up a machine which will represent as a recycling bin. Through problem identification, the objectives were identified as guides in the establishment of "Aluminum Can to WiFi Trading System with Metal Can and Plastic Bottle Collector and Monitoring System" for the school. This machine is designed to have a ramp and dimension that serves as the pathway of the collected metal cans and plastic bottles and houses a bin designated for each material. It is equipped with ultrasonic, inductive, and infrared sensors to sort, monitor, and count the metal cans and plastic bottles. It displays information, terms and condition, and transaction through the TFT LCD screen with three pushbuttons as its user input. It was installed with an Access Point that serves as the Network Address Translator to provide internet access to the user. This document proposes a project based on a microcontroller, with microelectronics devices namely, Ultrasonic Sensor (HCSR04), TFT LCD Display (MD070SD), IR proximity sensor, NPN Inductive Sensor LJ12A3-4-Z/BX NPN, an MG996R Servo and SG90 Micro Servo, ESP8266 node MCU, Arduino MEGA and push button. These have been programmed carefully and patiently tested to ensure its working conditions. The authors came up with an aluminum trading device in a robotic application with features such as access point, monitoring device, and sorting of metal cans and plastic bottles through well-planned design, data gathering, and reliability testing. The writers proved that the system is favorable and will support the school in managing the plastic bottles and metal cans used by the students.
\end{abstract}

Key words: Wi-Fi, Trading System, Bottle Collector, Monitoring System, Microcontroller, Sensors

\section{INTRODUCTION}

Waste production and management issues have been a major concern for many researchers in environmental studies [1].
Waste disposal is among the serious challenges affecting the society and the local authorities in the country. The RA 9003 law, the Ecological Solid Waste Management Act of 2001, tackled this problem by pushing for the participation of all industries, especially public bodies and the environment [2]. Solid waste management is a problem for urban authorities around the world, primarily because of the growing waste generation, the pressure on the local government due to the high costs correlated with its administration, lack of awareness of the variety of factors influencing the various phases of waste disposal and the interrelationships required to make the entire waste management system work [3].

Many human activities contribute to waste production and these domestic waste if they fail to be predisposed properly and in the right place, it can cause significant human problems and danger to the environment [4]. As the earth has become developed and technologically sophisticated waste levels are increasing, and the rapid rise in the quantity of waste produced [5] is a certain sign of more consumerism. Recycling is one of the most effective steps currently available to minimize these impacts and is one of the most competitive sectors in today's economy [6].

For the collection and use of solid waste, therefore, an efficient way is required, rather than relying on disposal alone. In a recent paper, they design and build a smart solid waste monitoring and collection system [7]. Their project consists of smart containers or intelligent bins, where every bin or box mounted on top of the container with Arduino Uno [8], an ultrasonic sensor [9], and a Radio Frequency ( RF) transmitter. If the bin is full of trash, it generates a signal to the control facility that will have the waste level in the bins and, via GSM / GPRS, a message (SMS) [10] will be sent to the truck driver's cell phone that is full of waste bin and needs to be cleared. Another paper is about how an automatic reverse vending aluminum can be thresher engineered and fabricated. This Automated Reverse Vending Aluminum Can Crusher (ARVACC) was able to achieve a high degree of trust in the criteria set for recognizing inserted aluminum cans [11].

The educational institution is required by law to educate people about solid waste management theories and practices. Awareness with participation is the key to engaging in an institution's solid waste management system to ensure the successful and efficient implementation of acceptable waste management practices [12]. Leveraging activated devices for 
educational purposes means providing WiFi connectivity at the school. However, keeping up with technical innovations may be a struggle for the academic system, but introducing WiFi in schools can play a significant role in making learning experience meaningful and engaging [13].

From there, the authors create a sorting bin program for metal can and plastic bottle collection that can recognize and sort items with LED and push button monitoring and control system, an MCU node for notification and access point, and servos for sorting metal bottles and plastic bottles. The convergence of these roles challenges the writers to come up with research that can benefit our community. This paper involves wireless devices communication technologies that are common today. Numerous wireless networking systems with different properties and markets such as IEEE 802.11, 3 G, and Long Term Evolution ( LTE) are available. It is necessary to know the basic properties of these technologies when deciding which technology to use for public Wi-Fi networks [14].

Practically everybody knows about the Pisonet idea. Replacing the traditional internet cafes in the $\mathrm{PH}$, particularly in low-income areas, is gradually controlled. There's also another sachet-type web business that can replace the typical Pisonet business strategy that eliminates the expensive machine stations and only provides $\mathrm{WiFi}$ internet connectivity [15]. Microcontroller such as Raspberry Pi [16] and Arduino [17] is the main device in this paper. This is how the trading system in this paper was conceptualized. This is how the trading system in this paper was conceptualized.

\section{MATERIALS AND METHODS}

\subsection{General System Design}

The general concept of this study is presented in figure 1 . The figure is the system architectures that explains the functionalities of the Aluminum Can to WiFi Trading System with Metal Can and Plastic Bottle Collector and Monitoring System. Figure 1 is the diagram that shows the left side as the inputs and the right side as the output while the microcontroller acts as the main controller of the device.

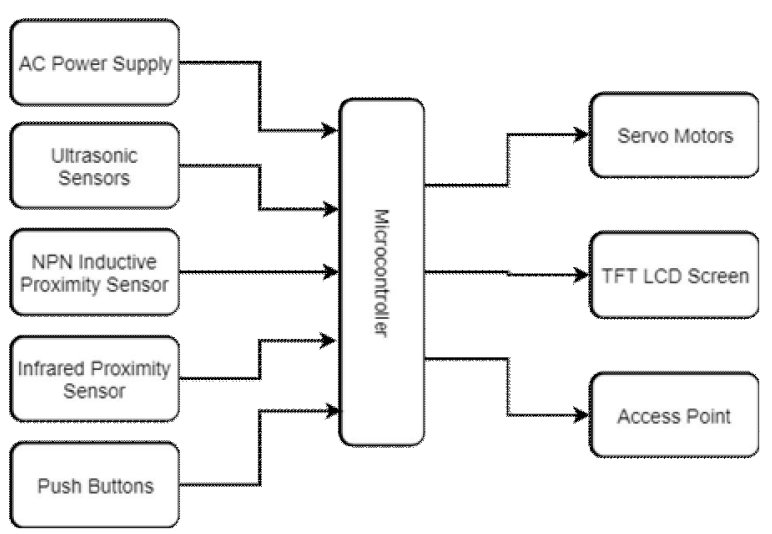

Figure 1: System Architecture of the Aluminum Can to WiFi Trading System with Metal Can and Plastic Bottle Collector and Monitoring System

\subsection{System Flowchart}

Figure 2 illustrates the brief function of the prototype. This is the step-by-step process of how the system works. It is comprised of sensors capable of detecting 3 major inputs which are plastic bottle, tin can, and aluminum can. The inductive sensor is in charge of the sorting system of the machine. The cans and bottles are detected by ultrasonic sensors allowing the machine to guide them using the servos. The infrared sensor counts the aluminum can. Finally, the LCD will display the SSID, password, and time. Then the user will access the internet through Access Point.

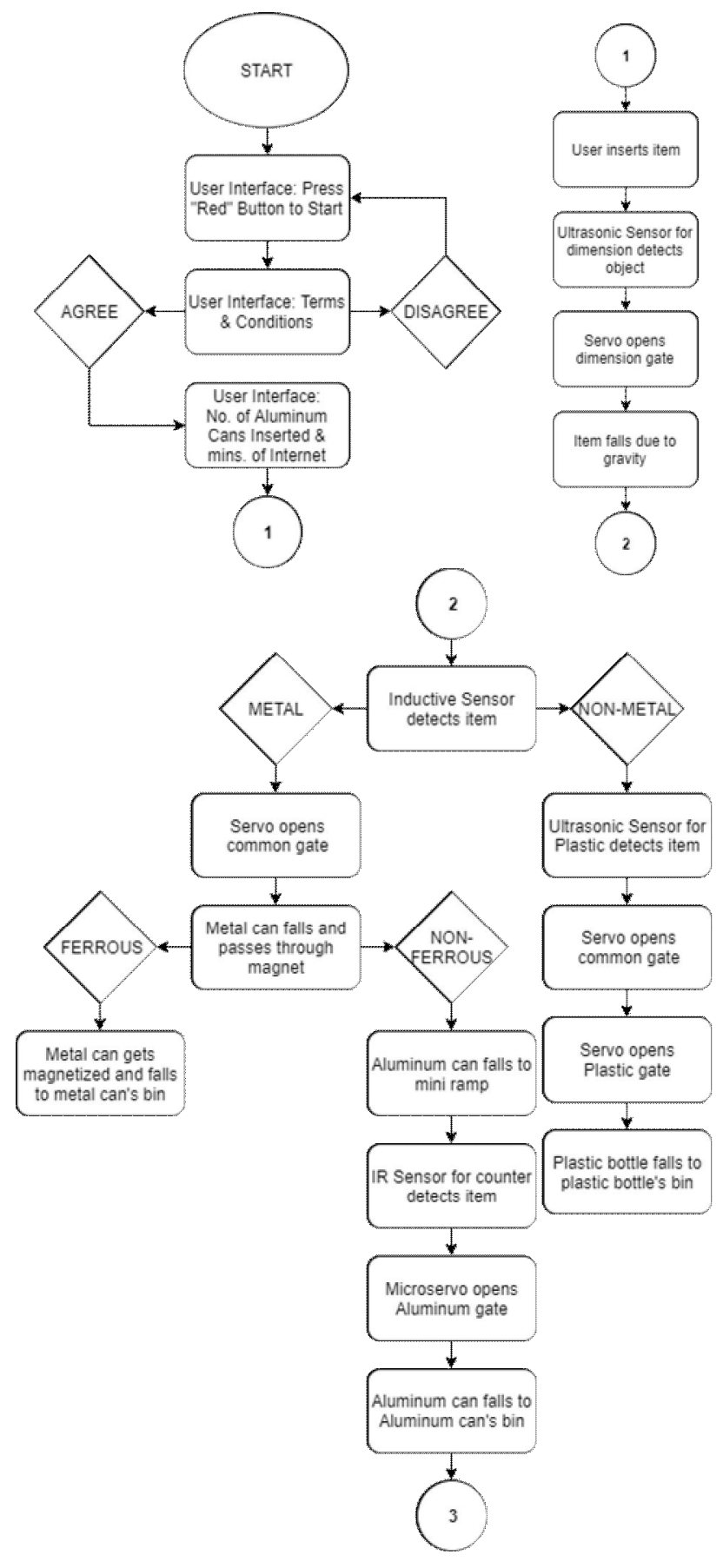




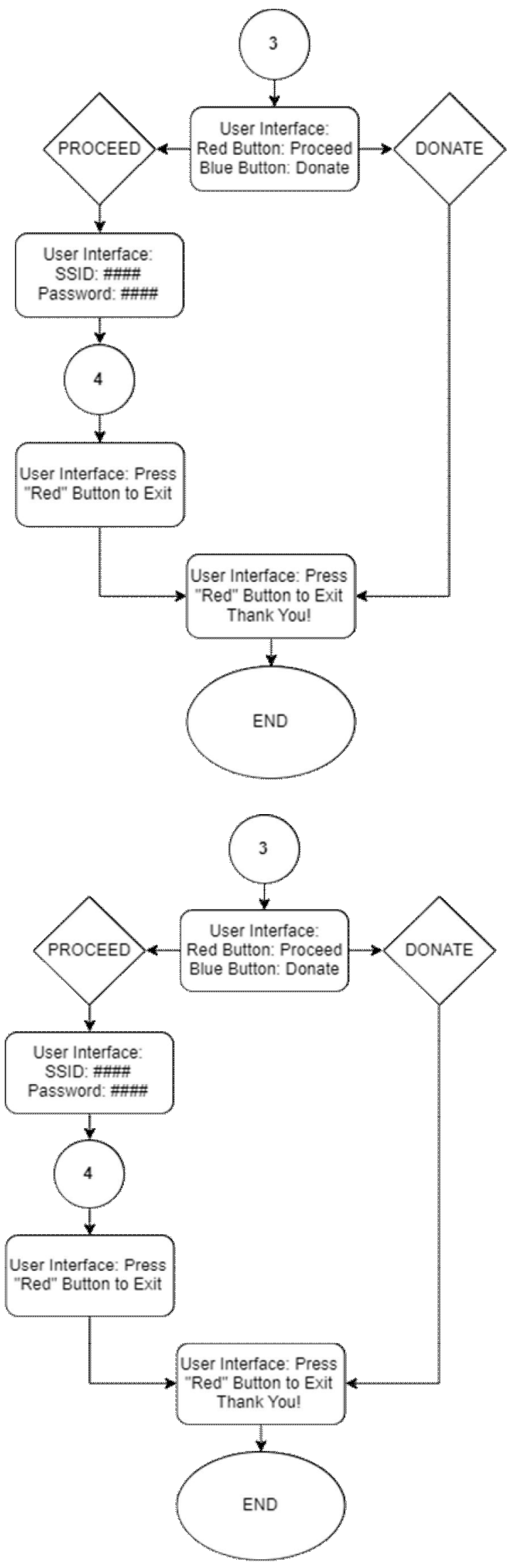

Figure 2: System Flowchart

\subsection{Wiring Systems}

Figures 3 and 4 are the wiring diagram of the circuit of the constructed prototype. It shows as a guide on how was each of the components was connected for the project. In figure 3.1, the primary device utilized is the Arduino Mega microcontroller that serves as the brain of all the electronics items that were connected. The infrared sensor, inductive sensor, and the ultrasonic sensor serve as the control input that activates various operations and initiates other devices such as the servo that govern the inputs into the bin., LCD that will display the information and transaction, and the Access Point that will provide the user internet access. In figure 3.2, the ultrasonic sensors serve as counters that send data to the Access Point.

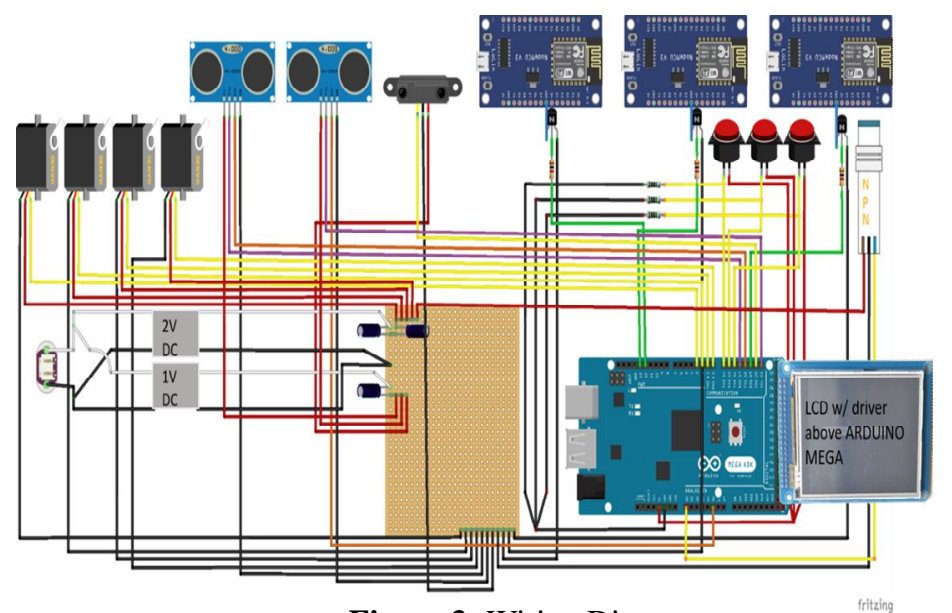

Figure 3: Wiring Diagram

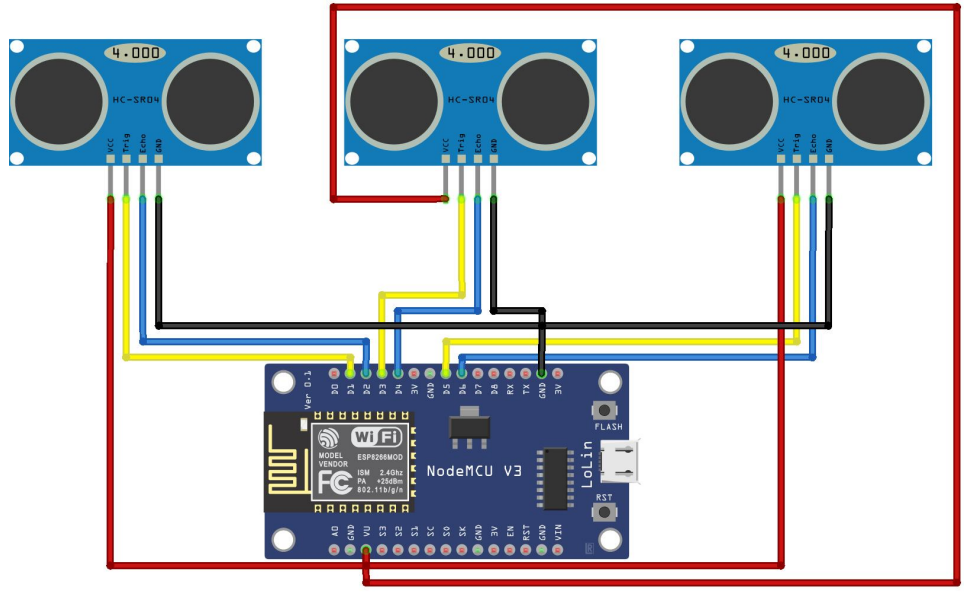

Figure 4: Wiring Diagram for Monitoring Systemfritzing

\section{RESULTS AND DISCUSSION}

One essential step in developing this paper is checking the prototype or the robot's functionalities. To arrive at a satisfactory performance it was put into many tests. Tests include unit testing, acceptance testing, and testing for integration. Unit testing has been conducted to determine all 
Edward Panganiban et al., International Journal of Emerging Trends in Engineering Research, 8(7), July 2020, 3639- 3644

of the elements used and to ensure that they all operate. Acceptance and integration testing ensured that everything was working according to its expectations. Comprehensive tests showing the robot 's integrity are specified in the tables presented.

\subsection{Results of Testing}

Table 1 shows the ultrasonic sensor dimension test. It shows the response of the ultrasonic sensor and servo with three different materials. The number of trials given in the table is just samples extracted from several trials made by the authors. There are 3 trials with plastic bottles, 3 trials with a tin can, and 4 trials with aluminum can be tested. If the ultrasonic sensor detects the material inserted in the dimension, the servo will open to collect the material.

Table 1: Ultrasonic Sensor Dimension Test

\begin{tabular}{|c|c|c|c|}
\hline TRIAL & MATERIAL & $\begin{array}{c}\text { ULTRASONIC } \\
\text { STATUS }\end{array}$ & $\begin{array}{c}\text { SERVO } \\
\text { STATUS }\end{array}$ \\
\hline 1 & Plastic Bottle & DETECTED & OPEN \\
\hline 2 & Plastic Bottle & DETECTED & OPEN \\
\hline 3 & Plastic Bottle & DETECTED & OPEN \\
\hline 4 & Tin Can & DETECTED & OPEN \\
\hline 5 & Tin Can & DETECTED & OPEN \\
\hline 6 & Tin Can & DETECTED & OPEN \\
\hline 7 & Aluminum Can & DETECTED & OPEN \\
\hline 8 & Aluminum Can & DETECTED & OPEN \\
\hline 9 & Aluminum Can & DETECTED & OPEN \\
\hline 10 & Aluminum Can & DETECTED & OPEN \\
\hline
\end{tabular}

Ultrasonic and inductive sensor segregation test was also established to determine the sorting function of the machine. Table 2 shows the result of the ultrasonic and inductive sensor segregation tests made by the authors. The number of trials given in the table is just samples extracted from several trials made by the authors. There are 3 trials with plastic bottles, 3 trials with a tin can, and 4 trials with aluminum can be collected. Here, it shows that when there is a plastic bottle, both servo will open. However, if the material is tin can or aluminum can, only the first servo will open.
Also, the inductive sensor can't detect the plastic bottle. Hence, the table has proven the good performance of segregation according to its desired function.

Table 3 shows the access point distance limit test to determine the range of the device. It shows that the access point shuts down when the user is disconnected. It also shows that the maximum range of the access point is 10 meters.

Table 3: Tabulated Access Point distance limit test.

\begin{tabular}{|c|c|c|c|}
\hline TRIAL & DISTANCE & PHONE STATUS & $\begin{array}{c}\text { ACCESS } \\
\text { POINT } \\
\text { STATUS }\end{array}$ \\
\hline 1 & 3 meters & CONNECTED & RUNNING \\
\hline 2 & 4 meters & CONNECTED & RUNNING \\
\hline 3 & 5 meters & CONNECTED & RUNNING \\
\hline 4 & 6 meters & CONNECTED & RUNNING \\
\hline 5 & 7 meters & CONNECTED & RUNNING \\
\hline 6 & 8 meters & CONNECTED & RUNNING \\
\hline 7 & 9 meters & CONNECTED & RUNNING \\
\hline 8 & 10 meters & CONNECTED & RUNNING \\
\hline 9 & 11 meters & DISCONNECTED & OFF \\
\hline 10 & 12 meters & DISCONNECTED & OFF \\
\hline
\end{tabular}

The Access Point time limit test (Table 4) shows that the access point will only turn off when there is no remaining time left. The remaining time is displayed on the LCD while the access point runs when the user accessed the internet.

Table 4: Tabulated Access Point time limit test.

\begin{tabular}{|c|c|c|}
\hline TRIAL & REMAINING TIME & ACCESS POINT STATUS \\
\hline 1 & $45 \mathrm{mins}$ & RUNNING \\
\hline 2 & $40 \mathrm{mins}$ & RUNNING \\
\hline 3 & $35 \mathrm{mins}$ & RUNNING \\
\hline 4 & $30 \mathrm{mins}$ & RUNNING \\
\hline 5 & $25 \mathrm{mins}$ & RUNNING \\
\hline 6 & $20 \mathrm{mins}$ & RUNNING \\
\hline 7 & $15 \mathrm{mins}$ & RUNNING \\
\hline 8 & $10 \mathrm{mins}$ & RUNNING \\
\hline 9 & $5 \mathrm{mins}$ & RUNNING \\
\hline 10 & $0 \mathrm{~min}$ & OFF \\
\hline
\end{tabular}

Table 2: Ultrasonic and Inductive Sensor Segregation Test

\begin{tabular}{|c|c|c|c|c|c|}
\hline TRIAL & MATERIAL & $\begin{array}{c}\text { INDUCTIVE } \\
\text { STATUS }\end{array}$ & $\begin{array}{c}\text { ULTRASONIC } \\
\text { STATUS }\end{array}$ & $\begin{array}{c}\text { SERVO1 } \\
\text { STATUS }\end{array}$ & SERVO2 STATUS \\
\hline 1 & Plastic Bottle & UNDETECTED & DETECTED & OPEN & OPEN \\
\hline 2 & Plastic Bottle & UNDETECTED & DETECTED & OPEN & OPEN \\
\hline 3 & Plastic Bottle & UNDETECTED & DETECTED & OPEN & OPEN \\
\hline 4 & Tin Can & DETECTED & DETECTED & OPEN & CLOSED \\
\hline 5 & Tin Can & DETECTED & DETECTED & OPEN & CLOSED \\
\hline 6 & Tin Can & DETECTED & DETECTED & OPEN & CLOSED \\
\hline 7 & Aluminum Can & DETECTED & DETECTED & OPEN & CLOSED \\
\hline 8 & Aluminum Can & DETECTED & DETECTED & OPEN & CLOSED \\
\hline 9 & Aluminum Can & DETECTED & DETECTED & OPEN & CLOSED \\
\hline 10 & Aluminum Can & DETECTED & DETECTED & OPEN & CLOSED \\
\hline
\end{tabular}




\subsection{Design Output}

Figure 4 shows the final design output of the Aluminum Can to WiFi Trading System with Metal Can and Plastic Bottle Collector and Monitoring System. It also displays the labeled position of an integrated component within. The device will operate if the AC located at the back of the unit is switched on. Every part is named and has its functionality. Its main body consists of plywood and glass to protect the electronic parts. Inside its case are the materials used such as ultrasonic sensor, infrared sensor, inductive sensor, nodeMCU, TFT LCD, push-button, servo, and three bins as storage for aluminum can, tin can, and plastic bottle.

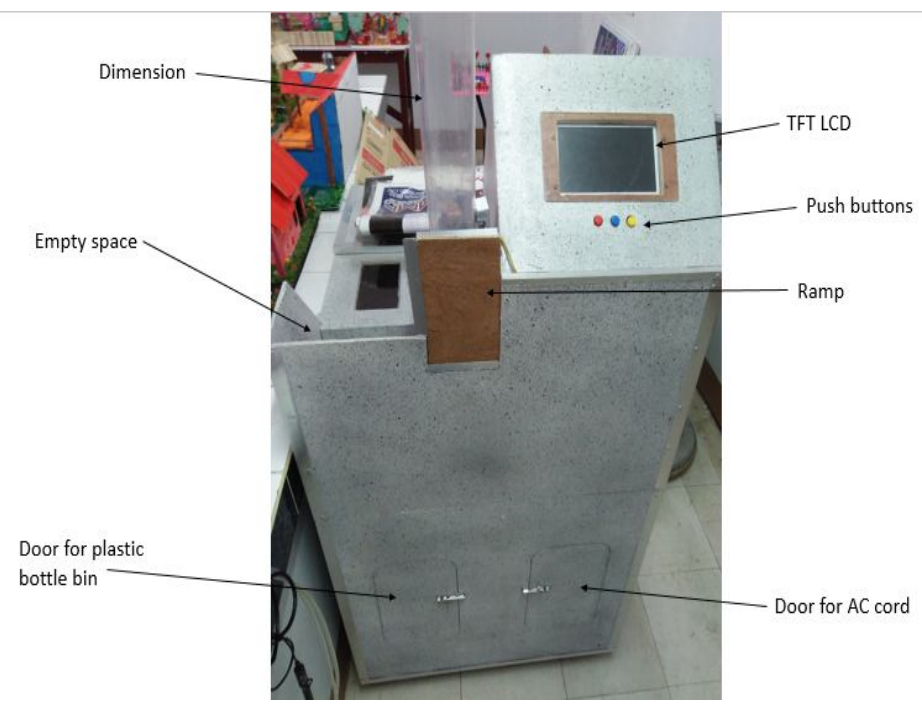

(a)

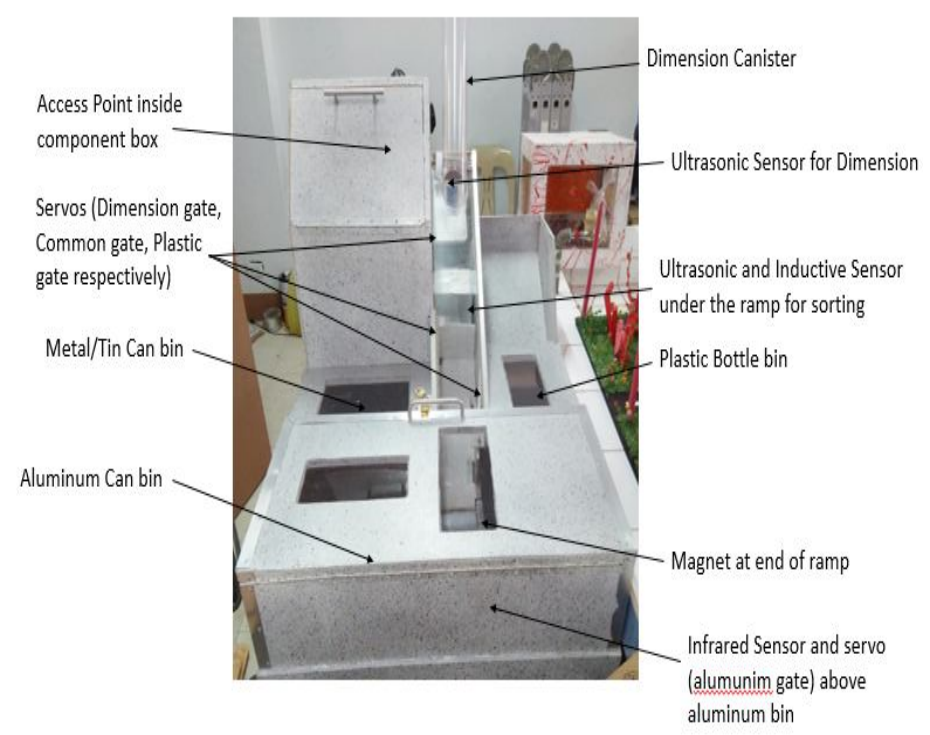

(b)

Figure 4: Final design output of the Aluminum Can to WiFi Trading System with Metal Can and Plastic Bottle Collector and Monitoring System (a) front view (b) back view

\section{CONCLUSION}

This paper described both the description of the device's configuration and the particulars of the research data which shows the device's desired outputs. The devices used throughout the process consist of sensors that could detect plastic bottles, tin cans, and aluminum cans. It is stationary and runs on $\mathrm{AC}$.

The project was made possible through different processes and steps and studies addressing the university staff's problems in collecting and segregating plastic bottles, metal cans, and aluminum cans. The project was proven working with its intended function. The researchers concluded that this project is reliable and is proven effective. This project can deal with plastic bottles, metal can and aluminum can management

\section{Acknowledgment}

The authors would like to give special thanks to Arthur Michael Abiad, Dorethy Jean De Vera, Dexter Gallema, and Moises Pataueg for the construction of the prototype and their assistance for this paper to become successful.

\section{REFERENCES}

[1] A. I. Afangideh, K. U. Joseph, and J. E. Atu, "Attitude of Urban Dwellers To Waste Disposal and Management in Calabar, Nigeria.," European Journal of Sustainable Development, vol. 1, no. 1, pp. 22-34, 2012.

[2] A. C. Mosqueda, "Successful Strategies To Generate Community Involvement In Solid Waste Management: Three Case Studies In The Philippines," 2008.

[3] L. A. Guerrero, G. Maas, and W. Hogland, "Solid waste management challenges for cities in developing countries," Waste Management, vol. 33, no. 1, pp. 220-232, 2013. https://doi.org/10.1016/j.wasman.2012.09.008

[4] P. C. A. Vivar, P. P. Salvador, and F. T. Abocejo, "Village-Level Solid Waste Management in Lahug, Cebu City, Philippines," The Countryside Development Research Journal, vol. 3, no. 1, pp. 96-108, 2015.

[5] J. McAllister, "Factors influencing solid-waste management in the developing world.," 2015.

[6] J. Hopewell, R. Dvorak, and E. Kosior, "Plastics Recycling: Challenges and opportunities," Philosophical Transactions of the Royal Society B: Biological Sciences, vol. 364, no. 1526, pp. 2115-2126, 2009. https://doi.org/10.1098/rstb.2008.0311

[7] S. A. Hassan, N. G. M. Jameel, and B. Sekerogu, "Smart Solid Waste Monitoring and Collection System," International Journal of Advanced Research in Computer Science and Software Engineering, vol. 6, no. October, pp. 7-12, 2016.

[8] E. B. Panganiban et al., "Real-Time Intelligent 
Edward Panganiban et al., International Journal of Emerging Trends in Engineering Research, 8(7), July 2020, 3639- 3644

Healthcare Monitoring and Diagnosis System Through Deep Learning and Segmented Analysis," IFMBE Proceedings, vol. 74, pp. 15-25, 2019.

https://doi.org/10.1007/978-3-030-30636-6_3

[9] E. B. Panganiban and J. C. Dela Cruz, "RFID-Based Vehicle Monitoring System," in HNICEM 2017 9th International Conference on Humanoid, Nanotechnology, Information Technology, Communication, and Control, Environment and Management, 2017, pp. 1-6.

[10] E. B. Panganiban, "Microcontroller-based Wearable Blood Pressure Monitoring Device with GPS and SMS Feature through Mobile App," International Journal of Emerging Trends in Engineering Research, vol. 7, no. 6, pp. 32-35, 2019. https://doi.org/10.30534/ijeter/2019/02762019

[11] N. T. Bugtai, A. K. B. Cham, E. V. Y. Fong, and T. A. Serrano, "Development of an Automated Reverse Vending Aluminum Cans Crusher Development of an automated reverse vending aluminum cans crusher," Science and Technology 2009 Congress and DLSU - Osaka University Workshop, no. September 2009.

[12] M. C. Paghasian, "Awareness and Practices on Solid Waste Management among College Students in Mindanao State University Maigo School of Arts and Trades," Advances in Social Science, Education and Humanities Research, vol. 128, pp. 5-12, 2017.

[13] M. Team, "The positive impact of WiFi at schools," 2016.

[14] I. Ullah, "A study and analysis of Public WiFi," 2012.

[15] J. Nieves, "After Pisonet, Here Comes Piso WiFi: A WiFi Vendo Machine, only in the PH," 2016.

[16] E. B. Panganiban, "Rainfall Measurement And Flood Warning Systems : A Review," International Journal of Scientific \& Technology Research, vol. 9, no. 03, pp. 244-254, 2020.

[17] E. B. Panganiban, "Automated hazardous gas detecting robot using wireless sensor networks with GSM-SMS alert and fire control system for households," International Journal of Advanced Trends in Computer Science and Engineering, vol. 8, no. 3, pp. 804-809, 2019.

https://doi.org/10.30534/ijatcse/2019/72832019 